\title{
Shifting the distribution of risk: results of a community intervention in a Swedish programme for the prevention of cardiovascular disease
}

\author{
Lars Weinehall, Göran Westman, Gideon Hellsten, Kurt Boman, Göran Hallmans, \\ Thomas A Pearson, Stig Wall
}

Department of Epidemiology and Public Health, Umeå University, S-901 85

Umeå, Sweden

L Weinehall

S Wall

Department of Family Medicine, Umeå

University, Umeå,

Sweden

G Westman

Norsjö Primary Health Care Centre, Norsjö, Sweden

G Hellsten

Department of Medicine, Skellefteå County Hospital and Umeå University,

Umeå, Sweden

K Boman

Department of Nutritional Research, Umeå University,

Umeå, Sweden

G Hallmans

Department of Community and Preventive Medicine, University of Rochester Medical Center, Rochester, New York, USA

$\mathrm{T}$ A Pearson

Correspondence to: Dr L Weinehall.

Accepted for publication 9 February 1998
Abstract

Study objective-To examine the impact of a systematic risk factor screening and counselling carried out by family physicians and family nurses within the larger framework of a community intervention programme for the prevention of cardiovascular disease (CVD).

Design-Quasi-experimental study comparing trends in an intervention area with those in a reference area.

Setting-A Northern Sweden municipality (5500 inhabitants) constituted the intervention area while the Northern Sweden region (510 000 inhabitants) served as the reference area.

Participants-All 30, 40, 50, and 60 year old inhabitants were invited each year from 1985 to 1992. Among 2046 eligible 1893 participated $(92.5 \%)$, which formed eight independent cross sections. One cross section, 1986, was re-surveyed forming a panel.

Main results-In the cross sections, mean total cholesterol was reduced from 7.09 to $6.27 \mathrm{mmol} / 1$ for men $(p<0.001)$ and from 7.13 to $5.89 \mathrm{mmol} / 1$ for women $(p<0.001)$ and mean systolic blood pressure from 132.2 to $123.7 \mathrm{~mm} \mathrm{Hg}$ for men $(\mathrm{p}<0.05)$ and from 129.2 to $122.0 \mathrm{~mm} \mathrm{Hg}$ for women $(p<0.001)$ during the eight years. Body mass index (BMI) increased from 25.6 to 26.2 for men $(p<0.05)$ and from 25.0 to 25.5 for women (NS). A corresponding reduction in cholesterol and blood pressure (for women) occurred in the panel, while BMI was unchanged. The risk for CVD, using the Framingham equation, was estimated to be reduced overall by $19 \%(p=0.0021)$ when comparing early cross sections $(1985 / 86)$ with the later cross sections (1990/91).

Conclusions-It was concluded that a long term community based CVD prevention programme that combines population and individual strategies can substantially promote a health shift in CVD risk in a high risk rural population. The individual attention and evaluation provided by the health provider survey seem to accelerate, but not increase the amount of, risk reduction.

(F Epidemiol Community Health 1999;53:243-250)

Prospective studies in different populations over the past 30 years have investigated the correlations between cardiovascular disease (CVD) risk factors and CVD morbidity and mortality. ${ }^{12}$ Epidemiological studies during recent decades have confirmed the necessity of further efforts to prevent CVD, especially in populations with a pronounced risk. In the US as well as in Europe, prevention programmes using a population oriented strategy to focus on the main risk factors have aimed to increase the public awareness of life style factors, to encourage changes in life style behaviours, and to shift the risk of the entire population to a lower level. In some of these programmes, high risk people have also been identified and counselled. A major unsolved question is whether the coronary heart disease and stroke incidence rates would improve further if the population wide strategy is combined with a strategy of detecting and treating people at higher risk. Among others, the Population Panel of the National Cholesterol Education Program (NCEP) hypothesised and anticipated a combined and compatible effect in their report by a simultaneous implementation of the two strategies. ${ }^{1}$ Some of the interventions have published results of evaluations, but mostly they have assessed the overall effect of the community intervention on CVD risk factors. ${ }^{3-9}$

The Västerbotten Intervention Program affords the opportunity to illustrate the effects of the population and the individual oriented strategy, separately and together. The Province of Västerbotten in Northern Sweden has, in relation to the entire country, higher CVD incidence and mortality rates. ${ }^{10-12}$ In response to a request from the county council in Västerbotten, a long term CVD prevention programme entitled the Västerbotten Intervention Program, was started in 1985. As there were no Swedish prototypes, the programme was designed drawing on experiences from other community interventions, in particular the North Karelia Project in Finland. ${ }^{13}$ One unique emphasis of the Västerbotten Intervention Program was to combine a population strategy with efforts to identify high risk people. Using the primary care system as a part of the community intervention, the project carried out systematic risk factor screening and counselling by its family medicine providers at the same time as the community intervention programme invoked other effects to raise public awareness. The main purpose of this paper is to examine the impact of a long term systematic risk factor screening and counselling carried 
out by family physicians and family nurses within the larger framework of a community intervention programme, and thereby explore if the health provider survey involved risk factor improvements, beside those of the populationbased intervention.

As an evaluation strategy it was decided to select as the study population a geographically well defined local area (Norsjö Municipality, 5500 inhabitants), and to use the population in MONICA (Multinational Monitoring of Trends and Determinants in Cardiovascular Diseases) Northern Sweden as the reference (about 510000 inhabitants). We describe changes in risk factors in those exposed both to the health provider survey risk factor screening and community intervention activities, compared with those exposed to the community intervention alone. Both will be compared with the reference area, which lacked corresponding intervention activities.

\section{Methods}

THREE STUDY GROUPS

The Västerbotten Intervention Program in Norsjö municipality: population strategy

The province of Västerbotten in Northern Sweden has a population of 260000 people. Within the province there are 15 municipalities. In Sweden the county councils are responsible for satisfying the inhabitants' need of health care, while the municipalities are responsible for environmental protection, child welfare, education, old age care, nursing homes, facilities for leisure time activities, and other social needs. The single municipality focused in this article, Norsjö, is one of the smaller, and constitutes a rural district. The CVD intervention programme in Norsjö was launched in 1984 under the auspices of the provincial county council.

At the time this study was carried out, all health care staff (including physicians) in Norsjö were employed by the Västerbotten County Council; three physicians, one dietitian, six district nurses, two laboratory assistants, and three medical secretaries were employed in Norsjö Primary Health Care (PHC). An arrangement between these primary care providers and the county council was established that defined the Norsjö PHC's long term responsibility for the comprehensive health provider survey as well as for the participation in the community-based public health activities. The intervention in Norsjö started in 1985 and will continue at least throughout the year 2000. The Norsjö Project combines both a population-based and an individually oriented strategy.

The population-based intervention concentrated on messages about life style factors (eating habits, alcohol, physical activity, and psychosocial factors), carried out by local associations, sport clubs, media, and food retailers. ${ }^{14}$ The programme was coordinated by a local collaborative committee, representing voluntary organisations as well as the Norsjö municipality executive board and the Norsjö PHC. To meet expressed public expectations and demands a great deal of attention has been paid to questions of nutrition. For example, at the beginning of 1987 a food labelling system was introduced in the grocery shops in Norsjö, where foods with a low fat and/or high fibre content were marked with a special heart symbol. The use of less usual health education activities and methods such as drama, music, and informal meetings were encouraged. Prevention was given more attention than previously in the local political debates. The Norsjö Project has had a great deal of publicity in local as well as in national newspapers and on radio/television. ${ }^{15}$ On the whole, the preventive work in Norsjö was accomplished within the framework of the existing community organisations and with almost no additional financial support.

The Västerbotten Intervention Program in Norsjö municipality: individual strategy

The cross sectional surveys-The individual strategy focused on traditional risk factors (plasma lipids, blood pressure, glucose tolerance, smoking, and body mass index) in defined age groups. All people 30, 40, 50, and 60 years of age, were invited annually to a health provider survey focusing on the traditional risk factors for CVD. As the health examination was intended to be an integral part of the community-based activities and, thereby, served as an opportunity for health communication, it was decided that the individual counselling performed by family physicians, district nurses, and dietitians should include all age eligible participants and not only people at higher CVD risk. Therefore all participants were individually given verbal information about their test results and provided with appropriate medical counselling. The Norsjö Project was supported by an advisory group from Umeå University, representing medicine as well as social science. This group provided scientific advice and developed the project guidelines that specified levels for active risk factor intervention, according to risk factor burden, age, and sex.

Among those screened for risk factors, the high risk persons received further medical and life style advice according to the project guidelines. The ordinary medical services at the health centre took care of those in need of medical treatment. All participants in the health provider survey were encouraged to participate in the community intervention and could, at their own initiative, reassess their blood pressure and lipids at the health centre. The proportions of people receiving antihypertensive and lipid lowering pharmacological treatment did not significantly change during the eight years of intervention reported in this study.

The Panel survey-To evaluate long term effects using the individual as level of analysis, the participants in the 1986 cross section survey were invited to a re-survey after two and after five years. In this individual follow up (Panel) each 1986 participant got a letter of invitation from the chief physician at the Norsjö health centre. The Panel surveys were carried out in the same way as the 1986 cross 
Table 1 Numbers invited and participants in the health survey in the study area and in the reference area

\begin{tabular}{|c|c|c|c|c|c|c|}
\hline \multirow[b]{2}{*}{ Year } & \multicolumn{3}{|c|}{ Intervention area } & \multicolumn{3}{|c|}{ Reference area } \\
\hline & Invited & Participants & $\%$ & Invited & Participants & $\%$ \\
\hline 1985 & 283 & 271 & 95.8 & & & \\
\hline 1986 & 272 & 260 & 95.6 & 2000 & 1625 & 81.3 \\
\hline 1987 & 268 & 258 & 96.3 & & & \\
\hline 1988 & 262 & 251 & 95.8 & & & \\
\hline 1989 & 247 & 232 & 93.9 & & & \\
\hline 1990 & 249 & 227 & 91.2 & 2000 & 1583 & 79.2 \\
\hline 1991 & 232 & 205 & 88.3 & & & \\
\hline 1992 & 233 & 189 & 81.0 & & & \\
\hline 1985-92 & 2.046 & 1.893 & 92.5 & & & \\
\hline
\end{tabular}

sectional survey and each participant was informed about the test results, got individual counselling and was once again encouraged to take part in the community intervention.

In a sub-study, the Panel participants were asked to assess the impact of the different community intervention activities performed in the local community, with respect to what personally influenced them. ${ }^{16}$ About half of the participants reported to have been influenced by the health survey $(58 \%)$ and by the counselling $(48 \%)$. Messages delivered by the local food labelling system (33\%) as well as a local public information letter $(28 \%)$ and the newspapers $(27 \%)$ were also reported to make considerable influence, while relatively few reported to be influenced by information at work (10\%), study circles $(6 \%)$, and public meetings $(5 \%)$.

The reference population

The two counties Norrbotten and Västerbotten in Northern Sweden, with a total population of
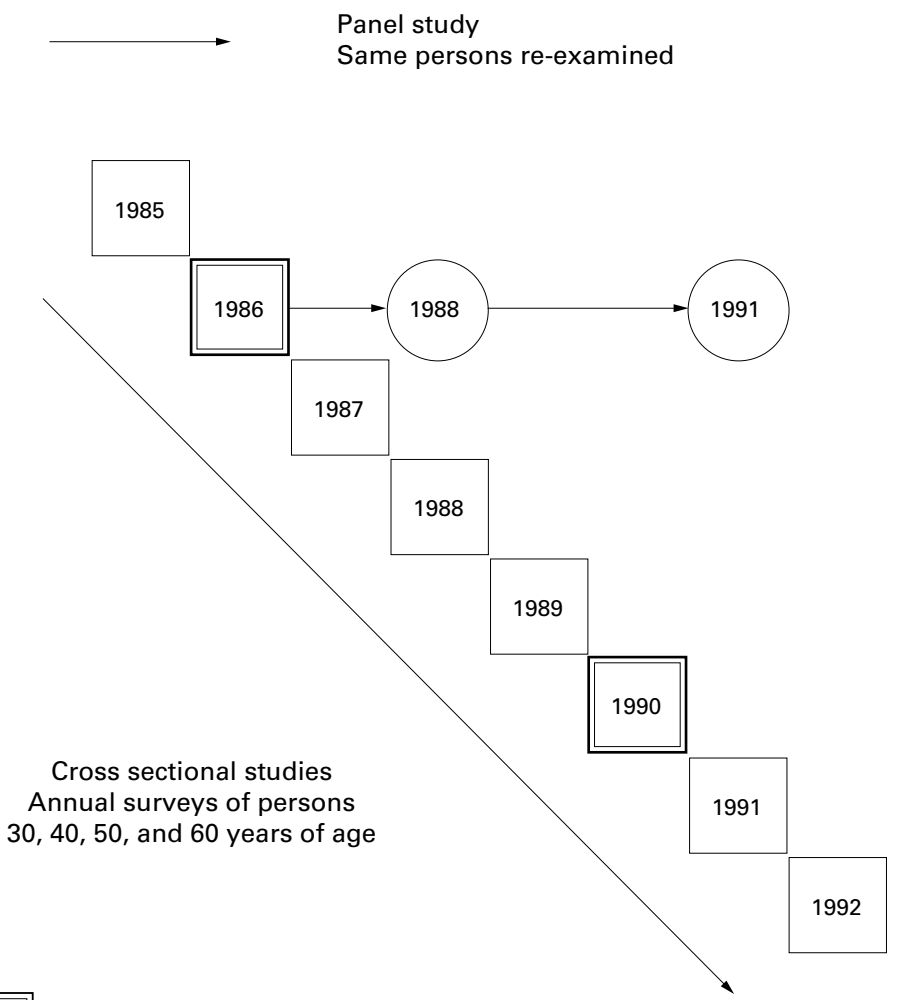

MONICA Survey

Figure 1 Overview of study groups.
510000 , served as the reference area. This population is one of those studied in the WHO project "Multinational Monitoring of Trends and Determinants in Cardiovascular Diseases" (MONICA). A total of 2000 inhabitants from the reference area, aged 25-64 years, were randomly selected from the population registers in 1986 and 1990 and invited to take part in a screening examination for cardiovascular risk factors (table 1). ${ }^{11}$ The health surveys in Norsjö were modelled to fit comparisons with the MONICA study.

\section{STUDY DESIGN}

The evaluation design in the Norsjö Project combines panel/(cohort) and cross sectional studies (fig 1).

In this paper risk factor changes in people exposed to health provider surveys and population based activities (the panel), are compared with those exposed to population based activities alone (the cross sections). Both will be compared with risk factor levels in populations not receiving any of these specific interventions, the Northern Sweden MONICA surveys.

\section{PROCEDURES OF DATA COLLECTION}

Blood pressure levels were recorded by means of a mercury random zero sphygmomanometer with the subject in a sitting position. Korotkoff's 5th phase was used as the diastolic pressure. Plasma samples for lipid measurements were obtained after a minimum of four hours of fasting and kept stored in a deep freeze blood bank at $-80^{\circ} \mathrm{C}$. The collected samples from each subject from the different cross sectional and panel surveys were analysed twice on the same occasion with the enzymatic method (Boehringer Mannheim GmbH, Mannheim, Germany) and a single average was calculated. In this way laboratory drift was controlled for as a possible explanation of changes in lipid levels. Weight was measured to the nearest kilogram and height to the nearest centimetre while subjects wore no shoes and were dressed in light indoor clothing. Body mass index (BMI) was calculated as weight $(\mathrm{kg}) /$ height $(\mathrm{m})^{2}$. Smokers were defined as those reporting daily smoking of cigarettes, cigarillos, cigars or a pipe. Those who reported that they were "occasional smokers" were classified as non-smokers.

The above methods were identical to those used in the reference population (Northern Sweden MONICA surveys).

\section{STATISTICS}

To account for aging over time in the panels and differences in age distribution among cross sectional surveys and the reference population, individual outcome measures were expressed as standard deviation $\mathrm{z}$ scores based on the age and sex specific averages of data from the MONICA 1986 surveys. An individual or mean $z$ value of 0 would thus correspond to the reference value after age and sex standardisation. Changes in outcome measures within the panel were assessed using ANOVA for repeated measurements. Time trends between the different cross 
Table 2 Means and p value for trend in CVD risk factors, cross sectional surveys, in intervention area $1985-1992$ and in reference area 1986 and 1990. (Mean $z=0$ for 1986 MONICA data). The original units displayed in the table are based on a retransformation of the $z$ scores

\begin{tabular}{|c|c|c|c|c|c|c|c|c|c|c|c|c|c|c|}
\hline \multirow[b]{2}{*}{ Outcome } & \multirow[b]{2}{*}{ Sex } & \multirow[b]{2}{*}{ Units } & \multicolumn{9}{|c|}{ Intervention area } & \multicolumn{3}{|c|}{ Reference area } \\
\hline & & & 1985 & 1986 & 1987 & 1988 & 1989 & 1990 & 1991 & 1992 & $p$ & 1986 & 1990 & $p$ \\
\hline \multirow[t]{4}{*}{ Cholesterol } & \multirow[t]{2}{*}{ Male } & z score & 0.56 & 0.24 & 0.18 & 0.04 & -0.14 & -0.35 & -0.16 & -0.08 & $\star \star \star$ & 0.00 & -0.05 & \\
\hline & & $\mathrm{mmol} / 1$ & 7.09 & 6.69 & 6.61 & 6.42 & 6.20 & 5.92 & 6.17 & 6.27 & & 6.37 & 6.30 & \\
\hline & \multirow{2}{*}{ Female } & z score & 0.63 & 0.13 & 0.25 & 0.11 & -0.08 & -0.42 & -0.06 & -0.33 & $\star \star \star \star$ & 0.00 & -0.21 & $\star \star \star$ \\
\hline & & $\mathrm{mmol} / 1$ & 7.13 & 6.48 & 6.63 & 6.46 & 6.20 & 5.77 & 6.24 & 5.89 & & 6.31 & 6.05 & \\
\hline \multirow{4}{*}{ Systolic blood pressure } & \multirow[t]{2}{*}{ Male } & z score & 0.12 & -0.14 & -0.43 & -0.25 & -0.23 & 0.02 & -0.50 & -0.41 & $\star$ & 0.00 & -0.01 & \\
\hline & & $\mathrm{mm} \mathrm{Hg}$ & 132.2 & 128.0 & 123.4 & 126.2 & 126.5 & 130.6 & 122.2 & 123.7 & & 130.3 & 130.1 & \\
\hline & \multirow[t]{2}{*}{ Female } & z score & 0.17 & 0.06 & -0.16 & 0.09 & -0.23 & -0.16 & -0.16 & -0.23 & $\star \star \star \star$ & 0.00 & -0.03 & \\
\hline & & $\mathrm{mm} \mathrm{Hg}$ & 129.2 & 127.2 & 123.1 & 127.2 & 122.0 & 123.2 & 123.3 & 122.0 & & 126.1 & 125.6 & \\
\hline \multirow[t]{4}{*}{ Diastolic blood pressure } & \multirow[t]{2}{*}{ Male } & z score & 0.35 & 0.24 & -0.02 & -0.27 & 0.20 & 0.39 & -0.14 & 0.11 & & 0.00 & 0.07 & \\
\hline & & $\mathrm{mm} \mathrm{Hg}$ & 85.5 & 84.4 & 82.0 & 79.3 & 84.0 & 85.9 & 80.6 & 83.1 & & 82.0 & 82.7 & \\
\hline & \multirow[t]{2}{*}{ Female } & z score & 0.22 & 0.42 & 0.12 & 0.04 & 0.17 & 0.11 & 0.25 & 0.29 & & 0.00 & -0.06 & \\
\hline & & $\mathrm{mm} \mathrm{Hg}$ & 81.3 & 83.6 & 80.2 & 79.4 & 80.8 & 80.3 & 81.4 & 82.2 & & 79.0 & 78.3 & \\
\hline \multirow[t]{4}{*}{ Body mass index } & \multirow[t]{2}{*}{ Male } & z score & -0.01 & -0.05 & -0.08 & -0.26 & 0.19 & 0.27 & 0.03 & 0.27 & $\star$ & 0.00 & 0.07 & \\
\hline & & $\mathrm{kg} / \mathrm{m}^{2}$ & 25.6 & 25.5 & 25.3 & 24.8 & 26.3 & 26.5 & 25.7 & 26.2 & & 25.6 & 25.9 & \\
\hline & \multirow[t]{2}{*}{ Female } & z score & -0.01 & 0.01 & -0.01 & 0.12 & 0.00 & 0.17 & 0.27 & 0.12 & & 0.00 & 0.00 & \\
\hline & & $\mathrm{kg} / \mathrm{m}^{2}$ & 25.0 & 25.0 & 24.9 & 25.5 & 25.0 & 25.7 & 26.2 & 25.5 & & 25.0 & 25.0 & \\
\hline \multirow[t]{2}{*}{ Daily smokers } & Male & per cent & 25 & 16 & 17 & 23 & 25 & 21 & 19 & 24 & & 23 & 23 & \\
\hline & Female & per cent & 18 & 24 & 26 & 20 & 26 & 24 & 21 & 20 & & 26 & 26 & \\
\hline
\end{tabular}

${ }^{\star} \mathrm{p}<0.05,{ }^{\star \star \star} \mathrm{p}<0.001$.

sectional surveys were in each study assessed by linear regression, while the significance of the differences in change between the studies were assessed by ANOVA. To evaluate the difference between participants and non-participants in the Panel, and for differences between 1986 and 1990 in the reference area, Student's $t$ test was used for categorical variables and $\chi^{2}$ test for differences between distributions. A value of $\mathrm{p}<0.05$ was regarded as statistically significant.

The study was approved by the Research Ethics Committee at the Umeå University and the data handling procedures by the National Computer Data Inspection Board.

\section{Results}

PARTICIPATION RATES

The Norsjö cross sections (population strategy)

Of a total of 2046 eligible subjects, 1893 participated $(92.5 \%)$ in the eight independent cross sections 1985-1992 (table 1). Five subjects were excluded because of missing data, and therefore the analysis included 1891 subjects. The health provider surveys were performed annually in late autumn by the same group of trained nurses and assistant nurses. The screening consisted of a questionnaire and a health examination. Within three months after the screening, each person got a personal invitation to make another visit at the Norsjö PHC, at which he or she were informed about the screening results and were advised according to their risk factor level.

\section{The Norsjö Panel (individual strategy)}

The participants in the 1986 cross sectional study (born in 1926, 1936, 1946, and 1956) formed a panel that was followed up on two occasions, in 1988 and 1991. Of 260 participants in the 1986 cross section survey, 10 inhabitants moved from Norsjö and 11 died until 1991. Therefore in 1991, 239 of those initially surveyed were still living in the Norsjö municipality. Of these, 187 participated in the 1988 follow up (78\%) and 183 in the 1991 analysis $(77 \%)$. A total of $154(64 \%)$ of the 1986 participants, did participate on all three occasions, forming the Panel reported in this presentation.
Men of the younger age groups (30 and 40 years) did not participate to the same extent as for the older age groups in each of the three surveys. While the mean age was 42 years among non-participants, it was 47 years among panel participants $(\mathrm{p}<0.001)$. The proportion of persons of low educational level was $68 \%$ among Panel participants compared with $47 \%$ among the non-panellists $(p=0.016)$. There was no difference in the panels between participants and non-participants concerning the initial level of blood pressure or BMI. The initial mean total cholesterol level was higher among participants $(6.69 \mathrm{mmol} / \mathrm{l})$ as compared with $6.48 \mathrm{mmol} / 1$ among non-participants. Of the 239 subjects in the 1986 survey, $19 \%$ were smokers. Among the 154 who participated on all three occasions $17 \%$ smoked in 1986 , while $24 \%$ of those who participated 1986 but were non-participants on the next two occasions, were daily smokers. Non of these differences were statistically significant.

\section{RISK FACTOR OUTCOME}

The cross sectional studies

Compared with the reference population (Northern Sweden MONICA Survey), the initial levels of total cholesterol and diastolic blood pressure were significantly higher in the study area for both men and women. After eight years there was a significantly decreased mean total cholesterol level and in systolic blood pressure for both men and women in the study area. At the same time, however, the mean BMI had increased for men (table 2). A retransformation of the $\mathrm{z}$ scores to the original units implies a reduction of the mean total cholesterol values by $12 \%$ for men, from 7.09 $\mathrm{mmol} / \mathrm{l}$ to $6.27 \mathrm{mmol} / \mathrm{l}(\mathrm{p}<0.001)$ and by $17 \%$ for women, from $7.13 \mathrm{mmol} / 1$ to $5.89 \mathrm{mmol} / 1$ $(p<0.001)$. With a corresponding calculation the reduction of the mean systolic blood pressure level was $6 \%$ for men, from $132.2 \mathrm{~mm} \mathrm{Hg}$ to $123.7 \mathrm{~mm} \mathrm{Hg}(\mathrm{p}<0.05)$ and $5 \%$ for women, from $129.2 \mathrm{~mm} \mathrm{Hg}$ to $122.0 \mathrm{~mm} \mathrm{Hg}$ $(\mathrm{p}<0.001)$. In the reference area the changes were generally modest, but female plasma cholesterol decreased significantly, $4 \%$ $(\mathrm{p}<0.001)$ (table 2). As the studies have 
Table 3 Trends in four CVD risk factors in the Norsjö 1986 Panel. (Mean $z=0$ for 1986 MONICA data). The original units displayed in the table are based on a retransformation of the $z$ scores

\begin{tabular}{|c|c|c|c|c|c|c|}
\hline Outcome & Sex & Units & 1986 & 1988 & 1991 & $\begin{array}{l}\text { p value, time } \\
\text { trend }\end{array}$ \\
\hline \multirow[t]{4}{*}{ Cholesterol } & \multirow[t]{2}{*}{ Male } & z score & 0.31 & -0.25 & -0.31 & \multirow[t]{2}{*}{ 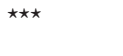 } \\
\hline & & $\mathrm{mmol} / 1$ & 6.77 & 6.06 & 5.98 & \\
\hline & \multirow[t]{2}{*}{ Female } & z score & 0.21 & -0.44 & -0.44 & \multirow[t]{4}{*}{$\star \star \star$} \\
\hline & & $\mathrm{mmol} / 1$ & 6.58 & 5.74 & 5.74 & \\
\hline \multirow[t]{4}{*}{ Systolic blood pressure } & \multirow{2}{*}{ Male } & z score & -0.29 & -0.28 & -0.52 & \\
\hline & & $\mathrm{mm} \mathrm{Hg}$ & 125.7 & 125.8 & 121.9 & \\
\hline & \multirow{2}{*}{ Female } & z score & 0.13 & 0.08 & -0.20 & \multirow[t]{12}{*}{ * } \\
\hline & & $\mathrm{mm} \mathrm{Hg}$ & 128.4 & 127.5 & 122.5 & \\
\hline \multirow{4}{*}{ Diastolic blood pressure } & \multirow{2}{*}{ Male } & z score & 0.21 & 0.08 & 0.12 & \\
\hline & & $\mathrm{mm} \mathrm{Hg}$ & 84.1 & 82.8 & 83.2 & \\
\hline & \multirow[t]{2}{*}{ Female } & z score & 0.46 & 0.41 & 0.23 & \\
\hline & & $\mathrm{mm} \mathrm{Hg}$ & 83.9 & 83.5 & 81.5 & \\
\hline \multirow[t]{4}{*}{ Body mass index } & \multirow[t]{2}{*}{ Male } & z score & -0.08 & -0.11 & -0.16 & \\
\hline & & $\mathrm{kg} / \mathrm{m}^{2}$ & 25.4 & 25.3 & 25.1 & \\
\hline & \multirow{2}{*}{ Female } & z score & 0.00 & 0.00 & 0.03 & \\
\hline & & $\mathrm{kg} / \mathrm{m}^{2}$ & 25.0 & 25.0 & 25.1 & \\
\hline \multirow[t]{2}{*}{ Daily smoker } & Male & per cent & 16.2 & 16.2 & 13.5 & \\
\hline & Female & per cent & 17.5 & 12.5 & 13.8 & \\
\hline
\end{tabular}

${ }^{\star} \mathrm{p}<0.05,{ }^{\star \star \star} \mathrm{p}<0.001$.

unequal but overlapping time periods, the significance of differences in change in cholesterol between intervention and reference populations was tested by comparing trends between equivalent years. The decline in the intervention area (based on combined cross sectional data from 1985 and 1986 and combined cross sectional data from 1989 and 1990) was significantly different from the decline in the reference population from 1986 to 1990 $(p<0.001)$. Over the eight years the proportion of daily smokers in the cross sections varied between $20 \%$ and $25 \%$ (table 2). There was, however, no significant smoking cessation trend over time.

The Panel

The Panel was surveyed three times, 1986, 1988, and 1991. The risk factor changes regarding total cholesterol were most pronounced during the first two years while the reduction in systolic blood pressure appeared later. The mean decrease in total cholesterol between 1986 and 1988 was $10 \%$ for men and $13 \%$ for women, while the decrease in systolic

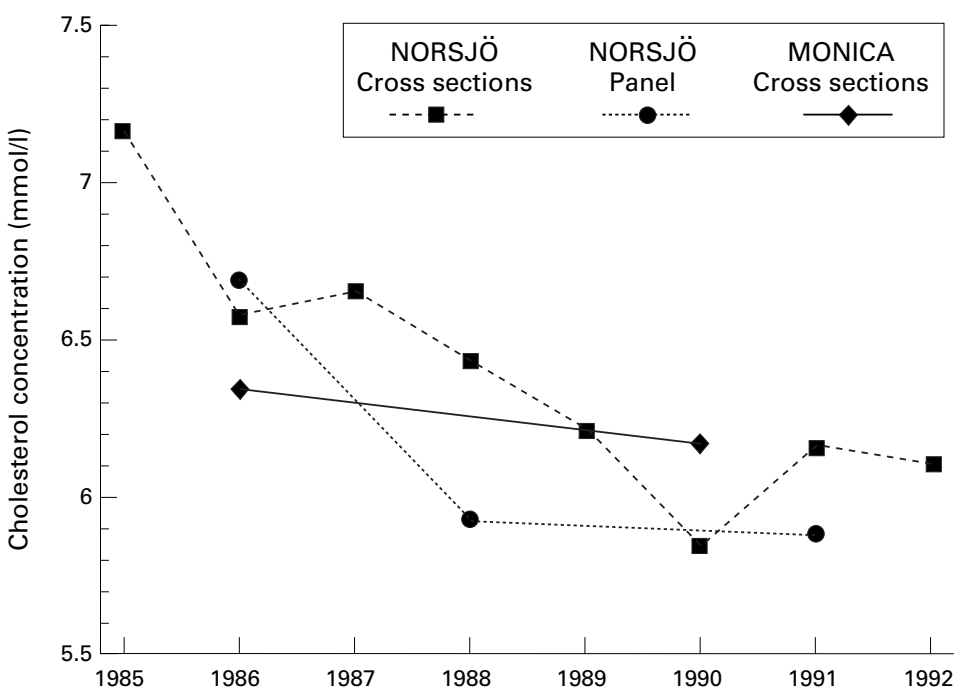

Figure 2 Plasma cholesterol in cross sections from 1985 to 1992 (dashed line) and panel 1986 (dotted line) in the intervention area, compared with trend between 1986 and 1990 in the reference population (continuous line). Original units retransformed from $z$ score.
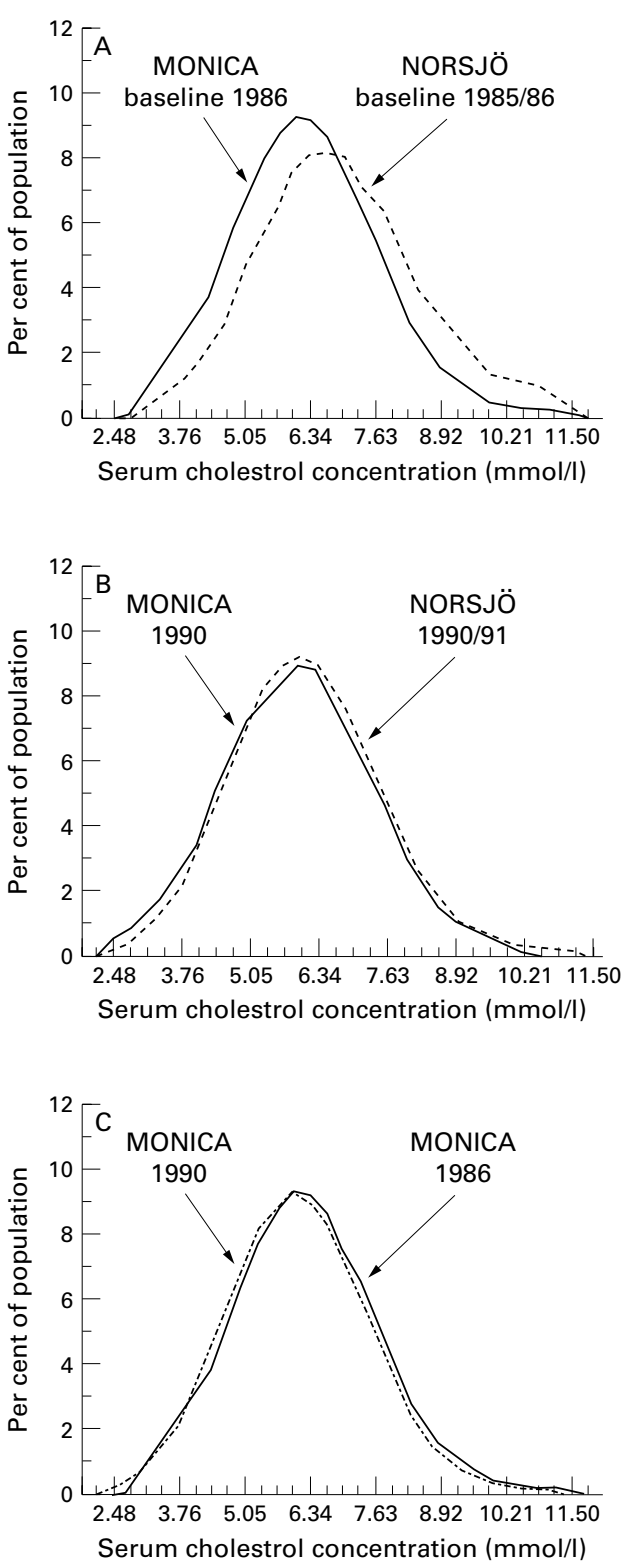

Figure 3 Cholesterol distribution in the intervention area (two pooled cross section surveys) compared with the reference area. Mean $z=0$ for 1986 MONICA $=6.34$ $\mathrm{mmol} / \mathrm{l}, S D=1.29$. (A) Initial distribution in the intervention area (dotted line) and in the reference area (continuous line). (B) Cholesterol distribution after five years intervention (dotted line) compared with cholesterol distribution in the reference area (continuous line). (C)

Cholesterol distribution in the reference area at the starting point (continuous line) and after four years (dotted line).

blood pressure between 1988 and 1991 was $3 \%$ for men and $5 \%$ for women. After five years the mean total cholesterol level and the systolic blood pressure level in the study area were lower $(\mathrm{p}<0.001$ and $\mathrm{p}<0.01$, respectively) than the corresponding reference area level (table 3). From an initial relatively high starting position, compared with the reference area, the Panel 1986 reduced their mean total cholesterol below the reference area value. Compared with the Norsjö cross section trend (using combined cross sectional data from 1985/1986 as baseline and combined cross sectional data from 1990/1991 as follow up) the declining trend is similar in Panel between 1986 and 

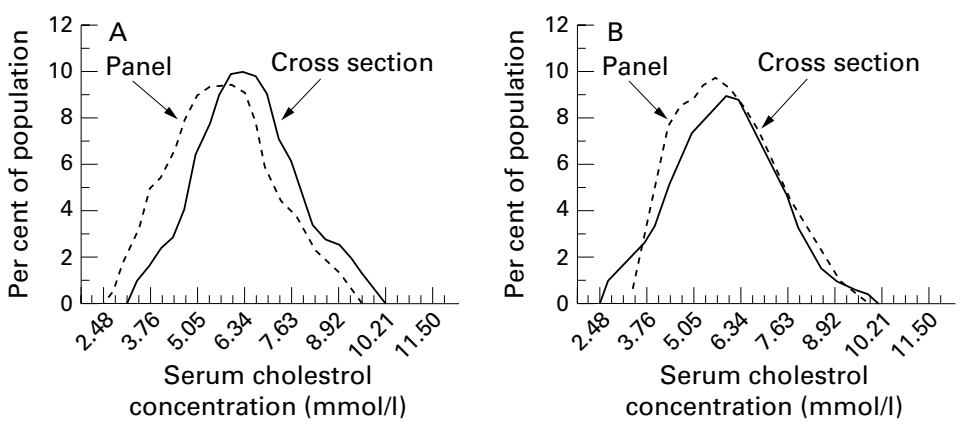

Figure 4 Distributions in plasma cholesterol, comparing panel with contemporaneous cross sections. Mean $z=0$ for 1986 MONICA=6.34 mmol/l. $S D=1.29$. (A) Comparison between panel (dotted line) and cross section (continuous line) after two years. (B)

Comparison between panel (dotted line) and cross section (continuous line) after five years.

1991, even if the cholesterol reduction occurred earlier in the Panel. When retransforming from $\mathrm{z}$ scores to original units, the five year follow up mean total cholesterol was 5.98 $\mathrm{mmol} / \mathrm{l}$ for men and $5.74 \mathrm{mmol} / 1$ for women.

There was no overall change in BMI. In the Panel the proportion of smokers decreased nonsignificantly from $17 \%$ to $14 \%$ during the five year period between 1986 and 1991 (table 3).

Cross sections and panel

In figure 2 the plasma cholesterol trend in the Panel and in eight cross sectional surveys are compared. The figure indicates different rates of change between the cross sections and the panel, thus the panel seemed to reach the reference area levels more rapidly, with the cross section catching up a few years later.

\section{The shifting distributions}

The implications of table 2 and table 3 are illustrated in figures 3 and 4 . Figure $3 \mathrm{~A}-\mathrm{C}$ display the total cholesterol distributions in the first cross sections in intervention area 1985/86 as well as in the 1990/91 cross sections. These distributions are compared with the coincident distributions in the reference area. As displayed in figure $3 \mathrm{~A}-\mathrm{C}$ there was a pronounced shifting to the left of the cholesterol distribution in the intervention area between the 1985 and the 1991 cross sectional survey. As the changes in distributions in the reference area during the corresponding time period were modest, the figure shows that the intervention area, with an initial less favourable cholesterol distribution, after 5-6 years developed a distribution quite identical to that of the reference population.

Figure $4 \mathrm{~A}$ and $4 \mathrm{~B}$ display the process in the intervention area, comparing panels and their contemporaneous cross sections. During the first two years of the five year panel, the cholesterol distribution for the panel participants shifted more compared with the cross section groups of 1988 (fig 4A). After three more years, however, the changes in the 1991 cross section caught up to the panel level (fig 4B), while the panel maintained the year 1988 level.

By using the Framingham coefficients for calculating the risk for cardiovascular disease, including age, sex, total cholesterol, systolic blood pressure, and daily smoking in the regression model,${ }^{17}$ the effect of these changes in risk factor burden in the Norsjö population is estimated: The probability that cardiovascular disease will occur in eight years in persons initially free of CVD was overall reduced by $19 \%(p=0.0021)$ when comparing the early cross sections in $1985 / 86$ with the $1990 / 91$ cross sections. The reduction among women was $23 \%(p=0.0052)$ and the reduction among men was estimated to be $17 \%(p=0.0331)$.

\section{Discussion}

This study carries three important messages. Firstly, it shows that inexpensive community CVD intervention is a possible way to support long term changes in risk factors in a population. The overall risk reduction during the intervention, according to the Framingham risk equation, seems to be larger in per cent than the difference in decline in single risk factors would imply. Secondly, it illustrates that community intervention might be useful in bringing late adopter populations up to mainstream health levels. Thirdly, it illustrates the potentials for positive change when the primary health care system is involved and plays a major part within a community intervention programme.

Rose has summarised three observations that imply that a CVD prevention programme ought to be based on a population approach: treating only those at highest risk makes little difference to the overall morbidity or mortality, the absolute number of people at high risk is determined by the overall distribution of risk in the population, and achieving change in those at highest risk is largely dependent on changing cultural attitudes in the whole population. ${ }^{18}$ Our study illuminates this interaction between the population approach and individually oriented preventive health provider surveys on the local level. While the long term cross sections reflect the trend in the population secondary to different prevention activities in the community, the panel trend indicates the effects of the individual educational screening performed by the primary care system.

The anticipated preventive combined effect of a community intervention concurrently with a high risk intervention has been proposed by the Population Panel of the National Cholesterol Education Program ${ }^{1}$ among others. Our data demonstrate this effect by comparisons between data from the cross sections and the panel.

It has previously been reported that the relative risk of having raised cholesterol in repeated cross sections in Norsjö dropped significantly between 1985 and 1990 in both sexes during the six years of intervention. ${ }^{14}$ Cross sectional data for the following two years show that the mean total cholesterol reduction was accompanied by a significant systolic blood pressure reduction. In this paper the cross sectional surveys were complemented by use of panel data as we were interested in comparing risk factor trends on the individual level with the population trend of cholesterol levels in the local community.

The participation rate in the cross sectional surveys was exceptionally high $(92.4 \%$ on the average) over the eight years. One explanation might be that the health surveys were offered 
by the ordinary primary health care centre including physicians and nurses that people already knew, trusted and relied on. Another explanation might be that the population had become more aware of CVD as a major health problem over decades.

The participants in the Panel were, compared with the non-participants, significantly older and lower educated, as younger people with higher education seemed less interested to join the follow up. This selection bias might help to explain some of the favourable results in the Panel, implying that the effectiveness of such an intervention can depend on its ability to reach people with low education and high risk levels. Thereby it is reasonable to suppose that a successful outcome in a community intervention, partly is depending on a high participation rate, as a higher rate means a higher representation of high risk groups, with larger preventive potential.

To evaluate the prevention programme alone a randomised controlled design was considered unethical, as it would imply that the primary care in the control area should neglect people at high risk. ${ }^{19}$ Instead, a reference population was considered more suitable to evaluation purpose, wherefore Northern Sweden became member of the WHO MONICA Project, serving both as valid reference population and as a basis to compare CVD incidence between regions. The MONICA Project Manual for health surveys was used for the guidance of the health surveys in the intervention area. To reduce measurement bias the health survey teams in the Northern Sweden MONICA, as well as the Norsjö team, participated in joint training and practice courses. With the Northern Sweden MONICA Project as reference, the Norsjö evaluation got a quasi-experimental design. Even if this design has advantages and disadvantages, ${ }^{20}$ it was estimated to be the most appropriate.

The intention in the different intervention activities was to tackle eating habits as well as smoking, alcohol habits and physical activity. However, by example, an analysis of main content in newspaper output during the first four years of the Norsjö programme illustrates that focus was on nutrition, as 83 of 96 of the newspaper articles (84\%) was about eating habits. ${ }^{15}$ This might explain why the effect mainly appeared in total cholesterol.

The overall results indicate that a substantial decrease in some CVD risk factors are possible to achieve and maintain during 5-8 years in a defined district with initially increased risk factors, compared with secular trends in the society. In our analysis the Framingham risk equation was used to estimate overall CVD risk, based on the risk factor distribution for 1985-86 and for 1990-91. Even if the Framingham equation from the early 1970 s is not completely applicable to predict CVD outcome in Northern Sweden today, it might serve as a useful tool when the same population is compared over time.

This study suggests an earlier, but not increased risk factor reduction when the population strategy is supplemented by individually
KEY POINTS

- For a community intervention to be successful, it needs to actively involve the health care sector.

- As a part of a community intervention programme, individual counselling seems to accelerate, but not increase the amount of, risk reduction.

- The cholesterol distribution in the whole population, can be shifted to the left by modifying life style factors.

- Community intervention might be especially suitable for late adopter populations to catch mainstream.

oriented primary care CVD screening and counselling. The individual advice seems to reinforce the effect of the health promotion activities in the general population. Both the cross sections and the panel show an overall advantageous trend in risk factor levels. It seems that the main effects on cholesterol occur relatively early followed by a later blood pressure reduction. Interestingly the cross sectional reduction in systolic blood pressure occurs despite an increase in BMI. The substantial reduction in total cholesterol may be of importance for the systolic blood pressure reduction. This finding merits further investigation.

The panel data suggest that there is considerable potential for the systematic health education and counselling performed by primary care physicians and nurses. This study is not an either/or study and the aim is not to play population-based activities off against individual oriented activities to find out what might be most effective. When interpreting the panel data, it is important to note that panel participants were likely also to have been in contact with the different health intervention activities in the local community. It is almost certain that health activities in the community interact with the individual counselling, and thereby create an overall facilitating and motivating atmosphere. It has been previously shown by Brännström $^{15}$ that the media reports about CVD prevention in Norsjö to a larger extent interest people in higher socioeconomic groups. It might be so that the individual counselling is more effective and adapted to the needs of lower educated, while higher educated are more disposed to be influenced by health promotion messages in media and in the public debate.

The success of an intervention might be underestimated by changes in risk factor levels because of aging in the study populations. By transforming to standard deviation score it was possible to explore the intervention effect in terms of confounding by the aging process. This method might be of particular relevance when evaluating the long term effect of a prevention programme where biomedical changes resulting from behavioural changes will occur relatively slowly.

It has not been easy to demonstrate risk factor reduction in community intervention programmes, and therefore the predominant 
opinion among many physicians has been that primary prevention is an inefficient way to reduce risk factor levels. As the community "turns first to its medical leaders when questions about health promotion arises", 9 it is vital to report experiences that indicate community intervention as a practicable strategy.

However, there have been some small scale quasi experimental studies evaluating community interventions in which the health care system played an active part in the intervention, thus demonstrating the possibilities with the population approach. ${ }^{352122}$ There are also several observational studies in which primary care physicians use the health surveys as an arena for communication with the public and as an instrument to identify high risk people. ${ }^{23-26}$ Results from these studies indicate that primary care can play an important part in CVD prevention, especially if the financial inducements are designed to promote prevention.

This study contradicts statements asserting that primary prevention programmes are useless or weak as influences on CVD risk factors. It also demonstrates that it is possible to move the distribution of risk factors towards a lower level (shift to the left) by a community intervention strategy. Such a study is, however, not easy to conduct. It is quite taxing on the patience of the medical personnel as well as on the people involved in the preventive programme. The model developed in one part of one country might not be easy to reproduce, as community intervention obviously depends to a large extent on unique and varying condition in the local community.

The effectiveness of community intervention is still under debate, especially as many large intervention programmes did not fulfil their initial expectations. ${ }^{27}$ It might be that the community intervention strategy is more suitable to affect a population characterised by a tendency to be late in adopting secular trends, than to advance an already favourable low risk population further. It might also be that one prerequisite for a successful community intervention is to involve actively the health care sector of the community in the intervention.

This paper suggests that the union of intervention at the community level and individually oriented preventive counselling strengthen each other. If people are repeatedly confronted with their health profile, primary care screening and prevention counselling can promote lasting risk factor changes. Health provider surveys and recurrent follow ups of persons at high risk may be justifiable both for society and for the health sector if, as our study suggests, these can be supported by health promotion activities in the local community, to achieve maximal beneficial risk factor reductions for the primary prevention of CVD.

Funding: this research was supported by grants from the Swedish Council for Planning and Co-ordination of Research, The Swedish Council for Social Science Research, the Swedish Federation of County Councils and the Swedish National Public Health Institute.

We thank the citizens in Norsjö who so willingly participated in the health examinations, and the personnel at the Norsjö Primary Care Centre for individual preventive counselling, data collection, and fruitful collaboration. We also thank the County Council of Västerbotten for its persistence in maintaining the Västerbotten Intervention Program.

1 Carleton RA (panel chairman). Report of the expert panel on population strategies for blood cholesterol reduction. on population strategies for

2 Wall S, ed. Cardiovascular disease - an epidemiological overview of magnitude, causes and preventive work. [In Swedish]. Stockholm, National Board of Health and Social Welfare, 1992.

3 Rossouw JE, Jooste PL, Chalton DO, et al. Communitybased intervention: The Coronary Risk Factor Study (CORIS). Int f Epidemiol 1993;22:428-38.

4 Vartiainen E, Puska P, Jousilahti P, et al. Twenty-year trends in coronary risk factors in North Karelia and in other areas of Finland. Int f Epidemiol 1994;23:495-504.

5 Epstein L. Israel's prevention programs and screening policies for cardiovascular disease. Public Health Rep 1984;99. $242-8$

6 Luepker RV, Murray DM, Jacobs Jr DR, et al. Community education for cardiovascular disease prevention: risk factor changes in the Minnesota Heart Health Program. Am $\mathcal{F}$ Public Health 1994;84:1383-93.

7 Abramson JH, Gifin R, Hopp C, et al. Evaluation of a community program for the control of cardiovascular risk factors: The CHAD program in Jerusalem. Isr $7 \mathrm{Med} S c i$ 1981;17:201-12.

8 Farquhar JW, Fortmann SP, Flora JA, et al. Effects of communitywide education on cardiovascular risk factors. The Stanford Five-City Project. $7 A M A$ 1990;264:359-65.

9 Mittelmark MB, Hunt MK, Heath GW, et al. Realistic outcomes: lessons from community-based research and demonstration programs for the prevention of cardiovascular diseases. Public Health Policy 1993;14:438-62.

10 Brännström I, Rosén M, Wall S, et al. Local health planning and intervention - the case of a Swedish municipality. Scand F Prim Health Care 1988; (suppl 1):57-64.

11 Huhtasaari F, Asplund K, Wester PO. Cardiovascular risk factors in the Northern Sweden MONICA Study. Acta Med Scand 1988;224:99-108.

12 Tunstall-Pedoe H, Kuulasmaa K, Amouyel P, et al. Myocardial infarction and coronary deaths in the World Health Organization MONICA Project. Registration procedures, event rates, and case fatality rates in 38 populations from 21 countries in four continents. Circulation 1994;90:583612.

13 Puska P, Nissinen A, Tuomilehto J, et al. The community based strategy to prevent coronary heart disease: conclusions from the ten years of the North Karelia Project. Annu Rev Public Health 1985;6:147-93.

14 Brännström I, Weinehall L, Persson LÅ, et al. Changing social patterns of risk factors for cardiovascular disease in a Swedish community intervention project. Int $\mathcal{F}$ Epidemiol 1993;22:1026-37.

15 Brännström I, Lindblad I-B. Mass communication and health promotion: the power of the media and public opinion. Health Communication 1994;6:21-36.

16 Strandman B. Changing citizen behaviour. Health and dietary information in a community based prevention programme. [Master's thesis]. Umea: Department of Epidemiology and Public Health, Umeå University, 1996.

17 Kannel WB, McGee FD, Gordon T. A general cardiovascular risk profile: The Framingham Study. Am $\mathcal{f}$ Cardiol 1976;38:46-51.

18 Rose G. The strategy of preventive medicine. Oxford: Oxford University Press, 1992

19 Tretli S, Bjartveit K, Foss OP, et al. Intervention on cardiovascular disease risk factors in Finnmark County: changes after a period of three years. Scand F Soc Med 1985;13:1-13.

20 Puska P, Tuomilehto J, Nissinen A, et al. The North Karelia Project. 20 year result and experiences. Helsinki: National Public Health Institute, KTL, 1995.

21 Murray D, Luepker RV, Pirie PL, et al. Systematic risk factor screening and education: a community-wide approach to prevention of coronary heart disease. Prev Med 1986;15: to preventic $661-72$.

22 Gutzwiller F, Nater B, Martin J. Community-based primary prevention of cardiovascular disease in Switzerland: methods and results of the National Research Program. Prev Med 1985;14:482-91.

23 Wrench J, Irvine R. Coronary heart disease: Account of a preventive clinic in general practice. $\mathcal{f} R$ Coll Gen Pract 1984;34:477-81.

24 Hellénius M-L, de Faire U, Berglund B, et al. Diet and exercise are equally effective in reducing risk for cardiovascular disease. Results of a randomized controlled study in men with slightly to moderately raised cardiovascular risk with slightly to moderately raised Atherosclerosis 1993;103:81-91.

25 Thorell B, Svärdsudd K. Intervention against ischaemic heart disease risk factors in the primary health care in a semi-rural disease risk factors in the primary health care in a semi-rural
community. The population study " 50 -year-old people in community. The population study "50-year-old peop

26 Björkelund C, Bengtsson C. Feasibility of a primary health care programme aiming at reducing cardiovascular and cerebrovascular risk factors among women in a Swedish community, Strömstad. Scand 7 Prim Health Care 1991;9: $89-95$.

27 Winkleby MA. The future of community-based cardiovascular intervention studies. Am f Public Health 1994;84: 1969-72 